\title{
Incidence and factors associated with outcomes of uterine rupture among women delivered at Felegehiwot referral hospital, Bahir Dar, Ethiopia: cross sectional study
}

Dawud Muhammed Ahmed ${ }^{1 *}$, Tesfaye Setegn Mengistu ${ }^{2}$ and Aemiro Getu Endalamaw ${ }^{3}$

\begin{abstract}
Background: Maternal mortality is a major public health challenge in Ethiopia. Uterine rupture is an obstetrical emergency with serious undesired complications for laboring mothers resulting in fatal maternal and neonatal outcomes. Uterine rupture has been contributing to high maternal morbidity and mortality. However, there is limited research on the factors and management outcomes of women with uterine rupture. Understanding the factors and management outcomes might delineate strategies to support survivors. Therefore the aim of this study is to assess the incidence and factors associated with outcomes of uterine rupture among laboring mothers at Felegehiwot Referral Hospital in Bahir Dar City, Northwest Ethiopia.

Methods: This is a cross sectional study with retrospective facility based data collection technique. All pregnant women who were managed for ruptured uterus at Felegehiwot referral hospital from September 112012 to August 302017 were included. The chart numbers of the women collected from operation theatre registers. Their case folders retrieved from the medical records room for analysis. Using structured check list, information on their sociodemography, booking status, clinical features at presentation and the place of attempted vaginal delivery was extracted. Data on the intraoperative findings, treatment, and associated complications and outcomes also collected. The collected data cleaned, coded and entered into EPI- Info version (7.1.2.0) and then exported in to SPSS Version 20.0 for analysis. Statistical comparison was done using chi square $\left(X^{2}\right)$. Strength of association between the explanatory variables and outcome variables described using odds ratio at $95 \% \mathrm{Cl}$ and $P$ value less than 0.05 . The results presented in tables.

(Continued on next page)
\end{abstract}

\footnotetext{
* Correspondence: muftidawud67@gmail.com

'Obstetrics and Gynecology, Bahir Dar University, College of Medicine and

Health Sciences, P. O box: 79, Bahir Dar, Ethiopia

Full list of author information is available at the end of the article
}

(c) The Author(s). 2018 Open Access This article is distributed under the terms of the Creative Commons Attribution 4.0 International License (http://creativecommons.org/licenses/by/4.0/) which permits unrestricted use, distribution, and reproduction in any medium, provided you give appropriate credit to the original author(s) and the source, provide a link to the Creative Commons license, and indicate if changes were made. The Creative Commons Public Domain Dedication waiver (http://creativecommons.org/publicdomain/zero/1.0/) applies to the data made available in this article, unless otherwise stated. 
(Continued from previous page)

Results: We studied 239 cases of uterine rupture in the 5 years period. Mothers without previous cesarean delivery including eight primigravidas took $87 \%$ of the cases. From all study participants, 54 of mothers (22.6\%) developed undesired outcomes whereas 185(77.4\%) discharged without major sequel. More than half (56.9\%) arrived in hypovolemic shock. Total abdominal hysterectomy was the commonest procedure accounting for $61.5 \%$. Duration of surgery was less than $2 \mathrm{~h}$ in $67.8 \%$ of the procedures. Anemia is the commonest complication (80.3\%) followed by wound infection and WF (11.7\% each). There were 5 maternal deaths (2.1\%). Mothers who had prolonged operation time (> 2 h) (AOR: 2.2, 95\% Cl: 1.10,4.63) were significantly associated with undesired maternal outcomes after management of uterine rupture.

Conclusion: Incidence of ruptured uterus and its complications were high in the study area. It reflects the need for improvement in obstetric care and strong collaboration with referring health facilities to ensure prompt referral and management.

Keywords: Ruptured uterus, Felegehiwot referral hospital, Undesired outcomes

\section{Background}

Uterine rupture is tearing of the uterine wall either partially or completely during pregnancy or delivery. This leads to extrusion of the fetus and /or placenta in to the maternal abdomen and massive hemorrhage especially when the rupture is of unscarred uterus [1-4], Uterine rupture contributes significantly to both fetal and maternal mortality, serous morbidities and loss of fertility from hysterectomy. The severity of fetal and maternal morbidity depends on the extent of uterine rupture [1, 5-7]. There is wide variation in incidence between developed and developing countries. In developing countries [8] the incidence is high due to socio economic factors, cultural practices and lack of access to antenatal and intra-partum care. This can be evidenced by the greater number of un-booked obstetric emergencies, often originating from rural areas with poor antenatal care [9], poor obstetric care [10, 11], few comprehensive emergency care facilities [2, 12], and poor socioeconomic status of the community $[6,13]$.

In Ethiopia for every 1000 births there are about 4 maternal deaths [14]. Uterine rupture with or without obstructed labor is the leading cause of maternal mortality accounting for $36 \%$ of the total maternal mortality [15]. This may be a reflection of high prevalence of home delivery $[5,15]$, especially in the rural areas. Majority of pregnant women in Ethiopia stay at home laboring for 2-3 days and come to health facility when they are seriously ill [15].

Previous caesarean section had been one of the leading cause of uterine rupture in developed countries, while uterine rupture from unscarred uterus is more prevalent in less and least developed countries [1, 7]. Studies conducted in the developing world give strong evidence that uterine rupture is a major health problem in these countries with the rate being high in rural areas [13]. A major factor in uterine rupture in developing countries is obstructed labour due to inadequate access to medical care $[2,3,16,17]$. Also the high incidence of contracted pelvis among black African women is found to be a high risk factor for obstetric complications. Other risk factors for uterine rupture include grand multiparity, instrumental delivery, and use of uterotonic drugs to induce or augment labour [5, 13]. Rarely placenta percreta and intrauterine manipulations such as internal podalic version and breech extraction can result in uterine rupture [1].

The type of surgical intervention on the uterus is dependent on the type and extent of rupture, hemodynamic status of the mother, desire for future fertility, presence of gross infection and experience of the surgeon. This could be total or subtotal abdominal hysterectomy, uterine repair with or without tubal ligation [3, 17-20]. Uterine repair should be reserved for women who have low transverse rupture, no extension of the tear to broad ligaments, cervix or vagina, easily controllable hemorrhage, good general condition, desire for future child bearing and no evidence of gross infection. Hysterectomy is appropriate for those with one of the above intra operative findings [17].

Uterine rupture is associated with a number of acute and long term complications. These include anemia, need for transfusion, bladder injury, wound infection, sepsis and death [19]. Complications like obstetric fistula, foot drop, psychological trauma, permanent loss of fertility are some of the long term outcomes [17, 18].Acute renal failure from pre renal azotemia is also possible following massive hemorrhage [9, 21].Among these, the most commonly encountered complication is hemorrhage leading to anemia $[3,5,18,19]$.

Not only this, Loss of fertility in communities where reproduction is considered the very essence of womanhood has grave socio cultural implications like divorce, and loss of economic support $[3,18]$.

Patients with fistula are living leaking urine or feces through the vagina. They have to continue living thereafter unclean, outcast, smelling of urine and 
faces. This is a cause for separate from their families, worsening poverty, malnutrition and almost unendurable suffering [22].

Maternal death as a consequence of uterine rupture occurs at a rate of $0-1 \%$ in modern developed nations, but the mortality rates in developing countries are $5-10 \%$ [17].

The determinant factors for maternal outcome of uterine rupture differ across geographical boundaries due to the difference in socio-demographic status, and the availability and accessibility of skilled birth attendant and health system effectiveness [5].

Once diagnosis of uterine rupture is entertained, the time spent for successful surgical intervention should be very short and all available resources should be quickly mobilized for favorable outcome of both mother and new born [17, 18].Late arrival and treatment increase the maternal and fetal morbidity and mortality [18]. Difficulty performing an exact diagnosis at the arrival of the patient with a severe diagnosis like uterine rupture may worsen the condition [13]. Immediate surgery and blood replacement plays major role in maternal survival [13, 18]. The main causes of maternal mortality in rupture uterus are failure to diagnose the condition at the first referral center and arrival at the tertiary center in a moribund condition [23]. The immediate cause of death in such condition includes puerperal sepsis [18] and hypovolemic shock [19].

Prognosis for the fetus is even worse than the mother [18]. Studies in different parts of developing countries indicated high fetal case fatality rate $[2,5,18$, 24]; complete uterine rupture being associated with the highest fetal death rate [18].

Initiation of labor at health institutions, early referral [2], and treatment of hypovolumia and prevention of postoperative anemia is recommended to decrease maternal death secondary to uterine rupture [5, 24]. In addition proper monitoring of labour and improvement of comprehensive emergence obstetric care at all levels of health care are recommended to avoid unnecessary delays in care [3].Early diagnosis and active surgical management will go a long way in reducing maternal and fetal mortality [9].

Uterine rupture remains an important clinical problem in northern Ethiopia. Changes in the cultural preference for home delivery, better transport and referral systems, and improved obstetric training and hospital management of laboring women are needed [20].

Currently the federal ministry of health of Ethiopia is improving obstetric care by scaling up of skilled personnel attended delivery; universal primary education, infrastructure and human resource development $[15,20,25]$. Despite these strategies births assisted by skilled provider in our country is 28\% [14]. This indicates the need for further research and implementation of programs to improve health status of the country.

\section{Statement of the problem}

The incidence of uterine rupture has regional and sub-regional variability posing a major public health problem in under developed countries [1,7]. The rate of pregnancy-related uterine rupture in women with unscarred uterus is $0.012 \%$ ( 1 in 8434) for women living in industrialized countries and $0.11 \%$ ( 1 in 920) for women living in developing countries [17].

In low resource settings multiple factors including educational status of women, ignorance, poverty, regular antenatal care checkup, home delivery, prolonged (dysfunctional) and obstructed labor had been identified risk factors of uterine rupture [21, 26]. Similarly evidences showed that previous cesarean delivery, mal-presentations [7, 27], induction and augmentation of labor [27], grand multiparty [7, 28], neglected labor, breech extraction, uterine instrumentation are predisposing factors for uterine rupture [7].

Evidences showed that abdominal pain, vaginal bleeding, loss of fetal station, non-reassuring fetal heart rate, shock and fetal bradycardia are most common indicators of uterine rupture [29]which needs prompt diagnosis and treatment before progressing serious maternal and perinatal outcomes $[7,30,31]$. Hemorrhage [7, 31], hypovolemic shock, need for blood transfusion [31], bladder injury, need for hysterectomy, and a maternal death are some of maternal consequences/outcomes while, admission to neonatal intensive care unit, fetal hypoxia or anoxia, and neonatal death are some of neonatal outcomes [7]. However, maternal/neonatal morbidity and mortality following uterine rupture depend on the level of medical care [7].

Although uterine rupture is preventable condition, it has also been one of the leading cause of maternal mortality in Ethiopia [15, 26]. The federal ministry of health is providing curative health services to the community as one of the priorities, and, as a consequence, the number of government hospitals in the country has increased from 126 to 31 . It is also trying to change the cultural preference of home delivery through better transport, access to prenatal care, obstetric training and exempted service charges for laboring mothers (2014 FMOH Bulletin). As part of this improvement Bahir dar university launched residency programs in Obstetric in 2014 using Felege hiwot referral hospital as affiliated site. There is a $24 \mathrm{~h}$ blood transfusion service and intensive care unit in the hospital. Despite all these, evidences are lacking as to the magnitude and factors for the outcome of uterine rupture in this area. In addition there was no effort to measure changes in management outcome as a result of 
improvement of obstetric services. Therefore the aim of this study is to identify factors associated with outcomes of uterine rupture among laboring mothers at Felegehiwot Referral Hospital in Bahir Dar City, Northwest Ethiopia.

\section{Literature review}

Uterine rupture has continued to be a catastrophic feature of obstetric practice especially in the low-resource settings [28].

There are some studies conducted in Ethiopia. Among these a prospective study over a period of 2 years at Debre Markos hospital found the incidence of ruptured uterus to be $3.8 \%$. Susceptible groups were age 25 to 29 years and grand multiparas $(>5)$. Complete type uterine rupture accounted for $88.6 \%$. In more than half $(54.3 \%)$ of the cases the site of rupture was anterior. The commonest procedure performed was hysterectomy (81.4\%). The postoperative complication rate was $24.3 \%$. Sepsis was the leading cause of death [16].

But more recently a review of uterine rupture cases at Ayder Referral hospital in Mekelle, northern Ethiopia between 2009 and 2013 found a rate of uterine rupture of 1 in 110 deliveries. Predisposing factors in order of their frequency were cephalopelvic disproportion (74\%), previous cesarean delivery (11\%), and fetal malpresentation (9\%). The presenting symptoms were pain, sudden cessation of contractions during labor and vaginal bleeding. The vast majority of ruptured uterus occurred from unscarred uterus; only five patients had undergone a previous cesarean delivery. The mean gravidity was 3.6. Less than two-thirds had received any prenatal care. Almost all patients came to Ayder from referring health facilities. One patient who had unrecognized ureteric injury and persistent anemia died. Perinatal mortality was $94 \%[20]$.

Analysis of the causes, complications and management outcomes of ruptured uterus in Dar-es- Salaam, Tanzania shows the incidence to be 2.25 per 1000 deliveries. The leading causes identified were obstructed labor, previous cesarean delivery and use of uterotonic drugs for induction and augmentation of labor. Most of these patients were referrals from municipal hospitals and all attended antenatal follow up at least once. There were 21 maternal deaths and 157 perinatal deaths giving case fatality rate of 12.9 and $96.3 \%$ respectively. The commonest maternal complication was hemorrhage (34.4\%) followed by sepsis, VVF and blood transfusions. Subtotal hysterectomy is the most common performed procedure $(73.6 \%)$, repair with BTL $(12.3 \%)$, repair only (12.3\%) and total hysterectomy (1.8\%). Most operations were made by obstetricians [3].

Rupture of the gravid uterus is still a significant cause of maternal mortality and morbidity in Nnamdi Azikiwe
University Teaching Hospital, Nnewi, Anambra State Southeast Nigeria. The incidence was 1 in 161 deliveries. The commonest age range of occurrence was 3034 years. Contrary to widespread belief that uterine rupture is a disease of multiparous women, in this study women of low parity predominate. Most of the ruptures were as a result a combination of risk factors like previous caesarean section with concurrent use of oxytocic. The commonest procedure performed was uterine repair only [32].

A 10 year retrospective study in the same hospital showed an incidence of $0.84 \%$. All the patients were multiparous and $63.8 \%$ were unbooked. Majority were Traumatic (iatrogenic) ruptures $(72.1 \%)$. Uterine repair with $(55.8 \%)$ or without (34.9\%) bilateral tubal ligation was the commonest surgery performed. The case fatality rate and perinatal mortality rate were 16.3 and $88.4 \%$ respectively. Average duration of hospitalization following surgery was 10.3 days [28].

There is also a retrospective study describing the factors influencing the management and the prognosis of ruptured uterus in a level III maternity care center of a third world country (Cocody University Hospital Center, Abidjan-Cote d'Ivoire). There were 513 cases of ruptured uterus between January 2002 and December 2014 giving an incidence of $0.95 \%$. Most cases occurred in women with unscarred uterus (76.8\%). Radical hysterectomy was done in $35.3 \%$ of all women. Uterine repair was done more commonly for women from the communes of Abidjan and its suburbs (71\%). Maternal mortality rate was $5.8 \%$ and factors like the type of surgery $(p=0.000)$, the time of uterine rupture $(p=0.000)$ and the transportation distance $(p=0.000)$ were significantly associated. Fetal mortality was $94.1 \%$ [8].

Study done in Sweden showed increased risk of uterine rupture (during their second delivery) in women who underwent a cesarean delivery compared with women who delivered vaginally in their first birth. Additional factors associated with increased risk of uterine rupture were induction of labor, high ( $>$ or $=4000 \mathrm{~g}$ ) birth weight, post term ( $>$ or $=42$ weeks) births, high ( $>$ or $=35$ years $)$ maternal age, and short $(<$ or $=164 \mathrm{~cm})$ maternal stature [33].

Researchers found the incidence of ruptured uterus to be $0.116 \%$ in one of the tertiary care hospital in Turkey. Trial of labor after cesarean was the most common cause of uterine rupture accounting for $31.1 \%$ of the cases. Vaginal Bleeding was the main symptom at presentation (44.3\%). Lower uterine segment (isthmus) was the most vulnerable part of uterus (39.3\%) for rupture. Women with delayed surgical intervention and older patients with increased parity were likely to have longer hospitalization periods [34]. 
One research in Zurich with special interest on effect of uterine fundal pressure on uterine rupture revealed previous uterine surgery as the main risk factor for uterine rupture in the whole study population. Risk factors in women with unscarred uterus were uterine fundal pressure (UFP), abnormal placentation, and age at delivery $>40$ years. The only factor which can be modified is Uterine Fundal Pressure [35].

Population based study in Sweden reported the overall rate of uterine rupture among women with an attempted vaginal birth in their second delivery to be $0.91 / 1000$. The rate of uterine rupture among women who attempted vaginal birth after a caesarean section was 9.00/1000 compared with a uterine rupture rate of 0.18/1000 among women without a history of caesarean delivery. Compared with women who experienced a spontaneous onset of delivery, women whose second delivery was induced faced a doubled increase in risk of uterine rupture. Induction of labor was associated with a doubled risk of uterine rupture both among women with a previous caesarean and among women who did not have previous caesarean. High maternal age, induction of labour, and high birth weight increased the risk of uterine rupture. The neonatal death rate was 51.09/1000. This was more than 60 fold increase compared with neonatal death rate among women without uterine rupture (1.4/1000) [36].

A population based study aimed at determining trends, risk factors and pregnancy outcome in women with uterine rupture compared all singleton deliveries with and without uterine rupture between 1988 and 2009. Uterine rupture occurred in $0.06 \%$ of all deliveries; $59 \%$ in women with a previous cesarean delivery. There was a gradual increase in the rate of uterine rupture from $1988(0.01 \%)$ to 2009 (0.05\%). Independent risk factors for uterine rupture were: previous $\mathrm{CD}$, preterm delivery ( $<37$ weeks), malpresentation, parity, and dystocia during the first and second stages of labor. In addition, Uterine rupture was noted as an independent risk factor for perinatal mortality [37].

Rupture of gravid uterus brings about potentially hazardous risks. Regular antenatal care, hospital deliveries and vigilance during labor with quick referral to a well-equipped center may reduce the incidence of this condition [34]. There is therefore a dire need for education of women on health-related issues, utilization of available health facilities, adequate supervision of labour and provision of facilities for emergency obstetric care [28].

Uterine rupture is a complication that can be eliminated under conditions of best obstetric practice. To attain this objective, use of misoprostol in primary health facilities should be stopped or proper management of the medication instituted. The survival of patients after uterine rupture depends on the time interval between rupture and intervention, and the availability of blood products for transfusion [38].

\section{Justification of the study}

Maternal and fetal morbidity and mortality is high in Ethiopia. Ruptured uterus contributes significantly to maternal mortality. In spite of this, there has been paucity of evidences on factors associated with management outcome of mothers who had uterine rupture. This study documents common complications and factors related with management outcomes of uterine rupture in FHRH. Therefore, the result of this study helps policy makers, program, planners, governmental and non-governmental organization implementers and maternal health service providers/practitioners to provide evidence based interventions which will contribute in maternal morbidity and mortality reduction in the hospital and the region as well. Most importantly, since there are limited research evidences on uterine rupture in the study area, this study serves as a baseline work for other researchers interested to work on the risk factors and outcomes of women who had uterine rupture.

\section{General objectives}

The objective of the study is to assess the incidence of uterine rupture and factors associated with outcomes of uterine rupture among women delivered in Felegehiwot referral hospital in Bahir Dar City, Northwest Ethiopia.

\section{Specific objectives}

- To determine the incidence of uterine rupture among women delivered at Felege hiwot referral hospital in the study period

- To identify complications after management of uterine rupture

- To identify factors associated with outcome of clients managed for uterine rupture in FHRH

\section{Methods \\ Study area and period}

Institutional based cross-sectional study was conducted from May 1 to 30, 2017 in Bahir Dar City, Felege Hiwot Referral Hospital. Bahir Dar is the capital city of Amhara National Regional State (ANRS), located $565 \mathrm{~km}$ Northwest of Addis Ababa. FHRH is one of the 42 governmental Hospitals in Amhara Regional state. The hospital serves for more than 5,000,000 populations in its catchment area (ANRHB 2015). The hospital has one big maternity ward which possesses around 74 beds. There are about 6000 deliveries per year, $30 \%$ of which is cesarean deliveries (prenatal report, 2016). There are 7 obstetricians, 27 residents and 25 midwives currently working in the department of obstetrics. As it is a referral hospital most of the clients are referral cases from health centers and district hospitals. 


\section{Study design}

Cross sectional study with retrospective facility based data collection was used.

\section{Source population}

Women who had uterine rupture (reached through their charts documented during the procedure).

\section{Study population}

Women who had uterine rupture in the time from September 112012 to August 302017 were included.

\section{Inclusion and exclusion criteria Inclusion criteria}

All women who had diagnosed with uterine rupture and managed at FHRH from 2012 to 2017 were included.

\section{Exclusion criteria}

Women who had uterine rupture and managed at other health facilities and referred to FHRH for complications like transfusion, ICU admission and Women who had ruptured uterus from medical termination of pregnancy in the second trimester, and those cases with missed data on outcome variable and major factors (parity, age, duration of labor, place of labor, operation factors...) were not included in the study.

\section{Sample size determination}

A single population proportion formula using the assumptions of $95 \%$ confidence level and 5\% margin of error was used to estimate the sample size. Estimated proportion of laboring at home among ruptured cases i.e. $57 \%(P=0.57)$ was used (Astatikie et al. [5]). Substituting the above assumption in the formula, the required sample size is calculated to be 376 .

$$
\begin{aligned}
& \mathrm{n}=(\mathrm{Z \alpha} / 2)^{2} \times \mathrm{p}(1-\mathrm{p}) / \mathrm{d}^{2} ; \text { Where } \\
& \mathrm{n}=\text { Sample size } \\
& \mathrm{Z} \mathrm{a} / 2=\text { Confidence level at } 95 \%=\mathbf{1 . 9 6} \\
& \mathrm{P}=\text { Proportion of population which is } 57 \%
\end{aligned}
$$

\begin{tabular}{llll}
\hline Factor & Proportion & Sample size & Reference \\
\hline Labor at home & $57 \%$ & $\mathbf{3 7 6}$ & Astatikie G et al. 2017 [5] \\
Hypovolemic shock & $34.3 \%$ & 346 & " \\
Post op anemia & $21.9 \%$ & 262 & "
\end{tabular}

\section{Sampling procedure}

First the main registration book of the Operation room where all emergencies registered according to their order was used to list all uterine rupture cases. Each of the cases included. The names of the mother's selected were checked from the charts and data was collected daily.

\section{Study variables \\ Dependent Variable:}

Outcome of uterine rupture

Independent variables

- Socio-demographic variables: age, address

- Obstetric factors: Parity, ANC status, previous cesarean delivery, obstructed labor, referral from health facility, induction and augmentation, place of trial of labor, blood pressure at arrival, anemia, duration of labor, type of rupture, type of surgical procedure and duration of surgery.

\section{Measurement}

The outcome variable was measured as desired outcome and undesired outcomes. The desired outcome was also measured as cured without major sequel (Yes, No). Women were classified as having undesired management outcome when she had developed one of the following condition: death, permanent organ injury, obstetric fistula, wound dehiscence, Sepsis, ICU admission.

Maternal death secondary to uterine rupture is defined as death of the mother from uterine rupture, its complications or management.

Sepsis: a woman will be declared she has sepsis if she is diagnosed and treated as recorded in the patient chart.

Operation time is defined prolonged if it took more than $2 \mathrm{~h}$.

Senior resident is a physician who is on fourth year of training in gynecology and obstetrics.

Source of admission is recorded as it is written from admission note.

Table 1 Socio demographic characteristics of uterine rupture in Felegehiwot Referral hospital from September 2012 to August 2017 $(n=239)$

\begin{tabular}{lll}
\hline Variables & Frequency & Percent \\
\hline Age of study participants & & \\
$<=16$ & 0 & 0.0 \\
$17-39$ & 229 & 95.8 \\
$\geq 40$ & 10 & 4.2 \\
Total & 239 & 100.0 \\
Address of study participants & & \\
Awi & 69 & 28.9 \\
Bahir dar Zuria & 28 & 11.7 \\
Metekel zone & 2 & 0.8 \\
West Gojjam & 53 & 22.2 \\
South Gondar & 87 & 36.4 \\
Total & 239 & 100.0 \\
\hline
\end{tabular}


Table 2 Obstetric variables of uterine rupture in Felegehiwot Referral hospital from September 2012 to August 2017( $n=239)$

\begin{tabular}{|c|c|c|c|c|c|}
\hline Variables & Frequency & Percent & (Continued) & & \\
\hline Gravidity & & & Variables & Frequency & Percent \\
\hline Primi gravida & 8 & 3.3 & Blood pressure on arrival & & \\
\hline Multi gravida & 157 & 65.7 & Non recordable & 53 & 22.2 \\
\hline Grand multi gravida & 74 & 31.0 & $<90 / 60 \mathrm{mmhg}$ & 83 & 34.7 \\
\hline Total & 239 & 100.0 & $\geq 90 / 60 \mathrm{mmhg}$ & 103 & 43.1 \\
\hline Gestational age & & & Total & 239 & 100.0 \\
\hline Preterm & 16 & 6.7 & Diagnosis on admission to $\mathrm{FHRH}$ & & \\
\hline Term & 164 & 68.6 & uterine rupture & 202 & 84.5 \\
\hline Post term & 30 & 12.6 & other diagnosis & 37 & 15.5 \\
\hline Unknown & 29 & 12.1 & Total & 239 & 100 \\
\hline
\end{tabular}

Antenatal care

$\begin{array}{cc}\text { No } & 53 \\ <4 & 68 \\ \geq 4 & 118 \\ \text { Total } & 239\end{array}$

Previous cesarean delivery

Yes

No

Total

100.0

53

68

118

239

31

Source of admission to $\mathrm{FHRH}$

Home

health center

district hospital

FHRH

Total

Duration of labor

$\begin{array}{cl}<24 \mathrm{~h} & 191 \\ 24-48 & 41 \\ >48 & 7 \\ \text { Total } & 239\end{array}$

Diagnosis on referral

uterine rupture

CPD/OL

Second stage

IUFD

other

No referral

Total

Time of arrival

Day

Night

Total
Table 2 Obstetric variables of uterine rupture in Felegehiwot Referral hospital from September 2012 to August 2017( $n=239)$

Time of arrival from 7:00 AM to 6:59 PM is labeled as "Day time", and 7:00 PM to 6:59 AM as "Night time".

\section{Data collection}

The folder numbers of the women who were managed for ruptured uterus over a 5 year period (September 11 2012-August 30 2017) was collected from operation theatre registers. Their case folders were retrieved from the medical records department. Using structured check list, information on their sociodemography, booking status, clinical features at presentation and the place of attempted vaginal delivery was extracted by the data collectors. Data on the intraoperative findings, treatment, associated complications and maternal outcomes were also collected. Check list checked by data collectors \& supervisors on daily base for completeness.

\section{Data processing and analysis}

Data was entered in to Epi Info version 7.1.2.0 and then transported to SPSS version 20 software packages for analysis. Descriptive statistics such as mean, percentage and standard deviation, was determined. Bi variable logistic regression was used to determine the association between each independent variable and the outcome variable. The degree of association between dependent and independent variables was determined using the OR with $\mathrm{CI}$ of $95 \%$ and $p$-value of $<0.05$.

\section{Data quality control}

Prior to data collection, the check list was tested to check the consistency of the checklist format and the ability of the data collector's performance. The checklist was modified based on the pretest results. One day training/ orientation how to carry out their duty was given for the data collectors. 


\section{Results}

There were a total of 262 cases of uterine rupture at FHRH in 5 years period from 2012 to 2017. The total number of deliveries in the same period was 28,835 . This gives an incidence of $0.9 \%$ ( 1 in 110). Among the uterine rupture cases, 10 charts were lost from card record room and additional 13 were rejected because of missing information. The final study population becomes 239 . Response rate becomes 91\%.

\section{Socio demographic characteristics of study participants}

Most of the study population (95.8\%) was in the age group of $17-39$. The mean age is 29.38 years. Most came from areas outside Bahir dar, Debub Gondar being the highest (36.4). There were 2 cases from Benshangul Gumuz region (Table 1).

\section{Obstetric variables}

Most are multigravidas with only eight uterine rupture cases among Primigravidas (3.3\%). Most of the ruptures occurred on unscarred uterus $(87 \%)$. Half of respondents have four and above Antenatal visits. $78 \%$ have attempted delivery at health centers. Ten uterine ruptures occurred at Felege Hiwot hospital. Uterine rupture was diagnosed correctly in $17.6 \%$ of cases up on referral. Most arrived with hypovolemic shock (Table 2).

\section{Presenting symptoms}

The three symptoms identified were abdominal pain (65.7), cessation of labor (56.5) and vaginal bleeding (45.65). The commonest presenting sign of uterine rupture is uterine tenderness (81.2\%). Fetal heart sounds were positive in $12.6 \%$ of cases (Table 3 ).

\section{Intra operative findings}

Anterior lower segment is the commonest site of uterine rupture accounting for $56 \%$. Total abdominal hysterectomy $(61.5 \%)$ leads from procedures performed. There

Table 3 Clinical presentations among cases of uterine rupture in Felegehiwot Referral hospital from September 2012 to August 2017 $(n=239)$

\begin{tabular}{lll}
\hline Symptoms & Frequency & Percent \\
\hline 1. Abdominal pain & 157 & 65.7 \\
2. cessation of labor & 135 & 56.5 \\
3. vaginal bleeding & 109 & 45.6 \\
4. tenderness & 194 & 81.2 \\
5. easily palpable fetal parts & 132 & 55.2 \\
6. uterine contraction present & 34 & 14.2 \\
7. FHB positive & 30 & 12.6 \\
8. Palpable defect on uterus & 56 & 23.4 \\
\hline
\end{tabular}

Table 4 Operative findings among cases of uterine rupture in Felegehiwot Referral hospital from September 2012 to August 2017 $(n=239)$

\begin{tabular}{|c|c|c|}
\hline Intra operative findings & Frequency & Percent \\
\hline \multicolumn{3}{|l|}{ Type of rupture } \\
\hline Complete & 203 & 84.9 \\
\hline Incomplete & 36 & 15.1 \\
\hline Total & 239 & 100.0 \\
\hline \multicolumn{3}{|l|}{ Site of rupture } \\
\hline Anterior lower segment & 134 & 56.1 \\
\hline Posterior & 19 & 7.9 \\
\hline Lateral & 78 & 32.6 \\
\hline Fundal & 8 & 3.3 \\
\hline Total & 239 & 100.0 \\
\hline Bladder injury & 8 & 3.3 \\
\hline Necrotic edges & 55 & 23.0 \\
\hline Vaginal extension & 64 & 26.8 \\
\hline \multicolumn{3}{|l|}{ Duration of surgery } \\
\hline$<=2 \mathrm{~h}$ & 162 & 67.8 \\
\hline$>2 \mathrm{~h}$ & 77 & 32.2 \\
\hline Total & 239 & 100.0 \\
\hline \multicolumn{3}{|l|}{ Type of Procedure } \\
\hline $\mathrm{TAH}$ & 147 & 61.5 \\
\hline STAH & 24 & 10.0 \\
\hline repair only & 54 & 22.6 \\
\hline repair with BTL & 14 & 5.9 \\
\hline Total & 239 & 100.0 \\
\hline \multicolumn{3}{|l|}{ Surgeon } \\
\hline consultant & 174 & 72.8 \\
\hline resident & 65 & 27.2 \\
\hline Total & 239 & 100.0 \\
\hline
\end{tabular}

were 8 bladder ruptures diagnosed intraoperative (Table 4).

\section{Complications}

Anemia is the commonest complication (80.3\%) followed by wound infection and VVF. There were 5 maternal deaths (2.1\%). Totally there were 54(22.6\%) mothers who developed undesired outcomes (Table 5).

Perinatal outcome: $84.1 \%$ of mothers end up in still birth. In 16 charts nothing is documented about the status of the neonate.

\section{Factors associated with outcomes of uterine rupture}

In multi variable logistic regression analysis it is found that mothers with operation times more than $2 \mathrm{~h}$ (AOR: 2.260, 95\% CI: $1.102,4.638$ ) were more likely to have undesired maternal outcomes than operation times less 
Table 5 Complications among cases of uterine rupture in Felegehiwot Referral hospital from September 2012 to August 2017 $(n=239)$

\begin{tabular}{|c|c|c|}
\hline Complications & Frequency & Percent \\
\hline \multicolumn{3}{|l|}{ Post op hemoglobin } \\
\hline$\geq 12 \mathrm{~g} / \mathrm{dl}$ & 47 & 19.7 \\
\hline $7-12 \mathrm{~g} / \mathrm{dl}$ & 169 & 70.7 \\
\hline$\leq 7 \mathrm{~g} / \mathrm{dl}$ & 23 & 9.6 \\
\hline Total & 239 & 100.0 \\
\hline \multicolumn{3}{|l|}{ Transfusion } \\
\hline No & 59 & 24.6 \\
\hline 1 units & 38 & 16.0 \\
\hline 2 units & 97 & 40.6 \\
\hline 3 units & 24 & 10.0 \\
\hline 4 units & 15 & 6.3 \\
\hline$>=5$ units & 6 & 2.5 \\
\hline Total & 239 & 100 \\
\hline Wound infection & 28 & 11.7 \\
\hline \multicolumn{3}{|l|}{ Hospital stay } \\
\hline$<8$ days & 160 & 66.9 \\
\hline$>=8$ days & 79 & 33.1 \\
\hline Total & 239 & 100.0 \\
\hline \multicolumn{3}{|l|}{ Undesired outcomes } \\
\hline ICU admission & 5 & 2.1 \\
\hline WF & 28 & 11.7 \\
\hline Sepsis & 12 & 5.0 \\
\hline Wound dehiscence & 15 & 6.3 \\
\hline Death & 5 & 2.1 \\
\hline
\end{tabular}

than $2 \mathrm{~h}$. Nearly one third (31.2\%) of those cases whose operation time was more than $2 \mathrm{~h}$, resulted in undesired outcomes. Gravidity, gestational age, place of attempted delivery, and time of arrival to Felegehiwot were not significantly associated with maternal outcomes (Table 6).

\section{Discussion}

The incidence of uterine rupture is $0.9 \%$ ( 1 in 110). This is lower than the 2012 incidence in this same hospital (2.9\% or 1 in 35 ) and the prevalence found at Debre Markos hospital 2.24\%(5) [39]. This may be as a result of establishment of functional district hospitals capable of managing these cases. But still it is higher when compared to incidence in other developing countries like $0.22 \%$ in Dar-es- Salaam, Tanzania and $0.057 \%$ in Imphal, India [3, 40]. This might be a reflection of delay in timely diagnosis of uterine rupture and referral once women reach health centers.

Most of the mothers in this study were referrals from health institutions (90\%). This is similar with the study in Dar selam, Tanzania where most patients were referrals from municipal hospitals. Despite the national report of high prevalence of home delivery in Ethiopia [5, 15] especially in the rural areas, in this study it shows only $5.9 \%$. The low figure of home delivery in this study may be a reflection of inappropriate assignment of those with referral papers as if they tried labor at health institution. But the common scenario is visiting health centers when they are seriously ill after laboring for 23 days at home. This affects the true figure of the problem. The other possibility may be inadequate supervision of labour and emergency obstetric care. Uterine rupture was diagnosed correctly in only $17.6 \%$ of the cases by referring health institution. This may be because of either difficulty in diagnosing uterine rupture or ruptures occur on the way to Felegehiwot.

There were 10 cases of uterine rupture at Felege Hiwot, none of whom developed undesired outcome. This may be due to prompt diagnosis, blood transfusion whenever necessary and immediate laparotomy indirectly reflecting the improved obstetric practice at this referral hospital.

Most underwent Total abdominal hysterectomy (62\% TAH), \& $10 \%$ had STAH. Around $75 \%$ of mothers from areas outside Bahir dar underwent hysterectomy whereas half from Bahir dar and its surroundings. This findings are consistent with the finding from Cocody University Hospital Center, Abidjan-Cote d'Ivoire which shows more conservative surgeries by uterine suture in women from the communes of Abidjan and its suburbs (71\%) versus $25 \%$ of women who came from inland towns [8]. However, in other studies the commonest procedure carried out was uterine repair only $[9,11,13$, 32]. Unstable hemodynamic status, more number of obstructed labors, presence of gross infection, and higher parities in our study may lead to hysterectomy.

Vesico Vaginal fistula (VVF) affected large proportion of mothers (11.7) who sustained uterine rupture similar with other studies [18]. However one study in India reveals a $2 \%$ risk [9]. The possible reason for this difference is high rate of obstructed labor in our study area, where as in India majority are following uterine scar.

Blood availability for transfusion as part of management of uterine rupture is lifesaving. In this regard $75.3 \%$ of study participants had blood transfusion and $40.6 \%$ got at least two units of cross matched blood. This is not usually possible in some countries. Even if all are anemic, only $57.1 \%$ of mothers got $500-1000 \mathrm{ml}$ blood transfusion at Al-thawra hospital, the main hospital in Sana'a City, the capital of the Republic of Yemen. This better blood availability in our study may indicate strong commitment of Federal ministry of health and continuous work of student clubs in mobilizing the community to donate blood. 
Table 6 Binary and multivariable logistic regression table for factors associated with outcome of uterine rupture in Felegehiwot hospital from September 2011 to August 2017( $n=239)$

\begin{tabular}{|c|c|c|c|c|}
\hline \multirow[t]{2}{*}{ Variables } & \multicolumn{2}{|c|}{ UR management outcomes } & \multirow[t]{2}{*}{$\operatorname{COR}(95 \% \mathrm{Cl})$} & \multirow[t]{2}{*}{ AOR $(95 \% \mathrm{Cl})$} \\
\hline & Undesired n (\%) & Desired n (\%) & & \\
\hline \multicolumn{5}{|l|}{ Gravidity } \\
\hline Primigravida & $4(7.4 \%)$ & $4(2.2 \%)$ & 1.0 & 1.0 \\
\hline Multigravida & $26(48.1 \%)$ & $131(70.8 \%)$ & $0.2(0.04-0.84)$ & $0.2(0.03,1.30)$ \\
\hline Grandmultigravida & $23(42.6 \%)$ & $45(24.3 \%)$ & $0.5(0.11-2.23)$ & $0.7(0.11,4.64)$ \\
\hline \multicolumn{5}{|l|}{ Gestational age } \\
\hline Preterm & $5(9.3 \%)$ & $11(5.9 \%)$ & 1.0 & 1.0 \\
\hline Term & $25(46.3 \%)$ & $139(75.1 \%)$ & $0.3(0.12-1.23)$ & $0.3(0.08,1.17)$ \\
\hline Post term & $8(14.8 \%)$ & $22(11.9 \%)$ & $0.8(0.21-3.02)$ & $0.5(0.11,2.46)$ \\
\hline Unknown & $16(29.6 \%)$ & $13(7.0 \%)$ & $2.7(0.74-9.79)$ & $2.6(0.63,11.52)$ \\
\hline \multicolumn{5}{|c|}{ Place of attempted delivery } \\
\hline Home & $6(11.1 \%)$ & $8(4.3 \%)$ & 1.0 & 1.0 \\
\hline Health Center & 40 (74.1\%) & $148(80.0 \%)$ & $0.3(0.11,1.09)$ & $0.6(0.16,2.47)$ \\
\hline District hospital & $8(14.8 \%)$ & $19(10.3 \%)$ & $0.5(0.14,2.15)$ & $0.8(0.17,4.24)$ \\
\hline \multicolumn{5}{|l|}{ Time of arrival to $\mathrm{FHRH}$} \\
\hline Day & $43(79.6 \%)$ & $121(65.4 \%)$ & 1.0 & 1.0 \\
\hline Night & $11(20.4 \%)$ & $64(34.6 \%)$ & $0.4(0.23,1.00)$ & $0.4(0.22,1.08)$ \\
\hline \multicolumn{5}{|l|}{ Duration of surgery } \\
\hline$<=2 \mathrm{~h}$ & $30(55.6)$ & $132(71.4)$ & 1.0 & 1.0 \\
\hline$>2 \mathrm{~h}$ & $24(44.4)$ & $53(28.6)$ & $1.9(1.06,3.72)^{*}$ & $2.2(1.10,4.63)$ \\
\hline
\end{tabular}

${ }^{*}$ statistically significant at $P-$ value $<0.05$

There were 5 maternal deaths $(2.1 \%)$ as a result of uterine rupture in the study period. This is lower as compared with deaths at Debre Markos hospital (6.6\%) and Cot devours $(5.8 \%)[5,8]$. Early diagnosis and management of uterine rupture, widely available blood transfusion services as well as close follow up post operatively may have contributed for this reduction. In this regard the hospital being teaching institution for the residency program, interns and residents could have a significant role.

According to research done at Abidjan, Cote d'Ivoire, maternal mortality was significantly influenced by the type of surgery $(p=0.000)$, time of uterine rupture $(p=$ $0.000)$ transportation distance $(p=0.000)$ [8]. In our study as well, four out of the five maternal deaths were from those treated with hysterectomies. This may be mainly due to the combination of more severe lesions in hysterectomies than repairs.

This study reveals that undesired outcomes were more likely to occur(two times) if time of operation took more than 2 h (AOR: $2.260,95 \%$ CI: 1.102, 4.638). Nearly one third $(31.2 \%)$ of those cases whose operation time was more than $2 \mathrm{~h}$, resulted in undesired outcome. This may be attributed to the complexity of the lesion in ruptured uterus and poor patient condition.

The age, source of admission, duration of labor before arriving FHRH, site and type of rupture, gestational age, and previous operations were not significantly associated with outcomes of uterine rupture.

The fetal outcome was poor with around $84 \%$ of still births. This is similar with other studies in developing countries [11]. There is Poor documentation about the baby that make difficult to analyze other factors.

\section{Conclusion}

This study shows high incidence of uterine rupture with significant undesired outcomes in Northwest Ethiopia. It reflects the need for improvement in obstetric care and strong collaboration with referring health facilities to ensure prompt referral and management.

\section{Limitations of the study}

Since the study is retrospective, 23 charts could not be included in this study because of missed variables and lost charts. Prospective multicenter study in the future will alleviate the limitations of this study.

\section{Abbreviations}

ANC: Antenatal care; ANRHB: Amhara National regional Health Bureau; ANRS: Amhara National Regional State; AOR: Adjusted odds ratio; BTL: Bilateral tubal ligation; CD: Cesarean delivery; CPD: Cephalo pelvic disproportion; FHRH: Felegehiwot referral hospital; FMOH: Federal Ministry of Health; ICU: Intensive care unit; IUFD: Intra uterine fetal death; MD: Medical doctor; MPH: Master of Public health; NICU: Neonatal Intensive Care Unit: OL: Obstructed labor; RH: Reproductive health; SPSS: Statistical package for 
social sciences; STAH: Sub total abdominal hysterectomy; TAH: Total abdominal hysterectomy; UFP: Uterine fundal pressure; WF: Vesico vaginal fistula; WHO: World Health Organization

\section{Acknowledgements}

We would like to express our gratitude to department of Gynecology and Obstetrics, School of Medicine, College of Medicine and Health Sciences, Bahir-Dar University for giving us this opportunity.

We are also indented to Felegehiwot Referral Hospital and its staffs for thei valuable time and genuine collaboration during this research process.

\section{Funding}

The fund for this research was obtained from Bahir Dar University. It was used for collecting data and writing the manuscript.

\section{Availability of data and materials}

The datasets used and analyzed during the current study are available from the corresponding author and can be obtained on a reasonable request.

\section{Authors' contributions}

DMA wrote the proposal; over sought the data collection, analyzed the data and drafted the paper. TSM participated in the proposal development, reviewed and interpreted the analysis. AGE revised the paper upon reviewers' comments and wrote the final manuscript. All authors read and approved the final version of the manuscript.

\section{Ethics approval and consent to participate}

Ethical approval was asked and exempted from the ethical committee of college of medicine and health sciences, Bahir Dar University. Permission letter to access charts of mothers for retrieving data obtained from Felegehiwot referral hospital medical directors office. Because the study was a retrospective chart review, informed consent from patients was not applicable. However, confidentiality was maintained when handling each case files. Personal identifiers were not included in the questionnaire. After the relevant data was collected from the charts of mothers, charts were returned back to their original place.

\section{Consent for publication}

Not applicable

\section{Competing interests}

The authors declare that they have no competing interests.

\section{Publisher's Note}

Springer Nature remains neutral with regard to jurisdictional claims in published maps and institutional affiliations.

\section{Author details}

'Obstetrics and Gynecology, Bahir Dar University, College of Medicine and Health Sciences, P. O box: 79, Bahir Dar, Ethiopia. ${ }^{2}$ Bahir Dar University College of Medicine and Health Sciences, Bahir Dar, Amhara Regional State, Ethiopia. ${ }^{3}$ Marie Stops International Ethiopia, Bahir Dar, Ethiopia.

Received: 10 January 2018 Accepted: 6 November 2018

Published online: 16 November 2018

\section{References}

1. Hofmey GJ, Say L, Gulmezoglu AM. WHO systematic review of maternal mortality and morbidity: the prevalence of uterine rupture. BJOG. 2005;112: 1221-8.

2. Aliyu SA, Yizengaw TK, Lemma TB. Prevalence and associated factors of uterine rupture during labor among women who delivered in Debre Markos hospital north West Ethiopia. Intern Med. 2016;6(4).

3. Kidanto HL, Mwampagatwa I, Van Roosmalen J. Uterine rupture: a retrospective analysis of causes, complications and management outcomes at Muhimbili National Hospital in Dar Es Salaam, Tanzania. Tanzan J Health Res. 2012;14(3):220-5.

4. Gabbe G, Niebyl JR, JLSimpson MBL, Galan HL, Jauniaux ERM, et al. Obstetrics: normal and problem pregnancies. 7th ed; 2017.
5. Astatikie G, Limenih MA, Kebede M. Maternal and fetal outcomes of uterine rupture and factors associated with maternal death secondary to uterine rupture. BMC Pregnancy Childbirth. 2017;17:117.

6. Mukasa PK, Kabakyenga J, Senkungu JK, Ngonzi J, Kyalimpa M, van Roosmalen J. Uterine rupture in a teaching hospital in Mbarara, western Uganda, unmatched case- control study. Reprod Health. 2013;10:29.

7. Vladimir Revicky AM, Mukhopadhyay S, Mahmood T. A case series of uterine rupture: lessons to be learned for future clinical practice. J Obstet Gynaecol India. 2012:62(6):665-73.

8. Loue VA, Dia JM, Effoh DN, Adjoby RC, Konan JK, Gbary EA, Abauleth RY, Kouakou F, Boni SE. Management and prognosis of uterine rupture during labor in an under-medicalized country: about 513 cases collected at the Cocody University hospital center (Abidjan-cote d'Ivoire). Int J Reprod Contracept Obstet Gynecol. 2015;4(5):1277-82

9. Sunitha K, Indira I, Suguna P. Clinical Study of Rupture Uterus - Assessment of Maternal and Fetal Outcome. J Dental Med Scie. 2015;14(3):39-45.

10. Dan K, Kaye OK, Nakimuli A, Osinde MO, Mbalinda SN, Kakande N. Lived experiences of women who developed uterine rupture following severe obstructed labor in Mulago hospital, Uganda. Reprod Health. 2014;11:31.

11. Nousheen Aziz SY. Analysis of uterine rupture at university teaching hospital Pakistan. Pak J Med Sci. 2015;31(4):920-4.

12. Igwegbe $A O$, Eleje $\mathrm{GU}$, Udegbunam OI. Risk factors and perinatal outcome of uterine rupture in a low-resource setting. Niger Med J. 2013:54(6):415-9.

13. Ishraq Dhaifalah JS, Fingerova $\mathrm{H}$. Uterine rupture during pregnancy and delivery among women attending the Al-Tthawra hospital in Sana'a city Yemen Republic. Biomed Pap Med Fac Univ Palacky Olomouc Czech Repub. 2006;150(2):279-83.

14. Survey EDaH. Key indicators report. In: CSACEa, editor. ICF. Addis Ababa; Rockville: CSA and ICF; 2016

15. Yifru Berhan $A B$. Causes of maternal mortality in Ethiopia: a significant decline in abortion related death. Ethiop J Health Sci. 2014;24(0 suppl):15-28.

16. Admassu A. Analysis of ruptured uterus in Debre Markos hospital, Ethiopia. East Afr Med J. 2004;81(1):52-5 PubMed PMID: 15080517. Epub 2004/04/15. eng.

17. Gerard G, Nahum M, FACS. Uterine Rupture in Pregnancy: FACOG, FACS; 2016.

18. Yasmeen Khooharo JZY, Malik SH, Amber A, Majeed N, Malik NH, Pervez H, Majeed I, Majeed N. Incidence and management of rupture uterus in obstructed labour. J Ayub Med Coll Abbottabad. 2013;25:1-2.

19. Ahmed MA, Elkhatim GES, Ounsa MAA/GE, Mohamed EY. Rupture uterus in sudanese women: management and maternal complications. World J Pharm Pharmaceut Sci. 2015;4(04):1669-75.

20. Berhe $Y$, Gidey $H$, Wall LL. Uterine rupture in Mekelle, northern Ethiopia, between 2009 and 2013. Int J Gynaecol Obstet. 2015;130(2):153-6 PubMed PMID: 25935473. Epub 2015/05/04. eng

21. Mahbuba IA. Uterine rupture -- experience of 30 cases at Faridpur medica college hospital. Faridpur Med Coll J. 2012;7(2):79-81.

22. AbouZahr CDC. Global burden of obstructed labour in the year 2000 evidence and information for policy (EIP). Geneva: World Health Organization; 2003.

23. Ofir K, Sheiner E, Levy A, Katz M, Mazor M. Uterine rupture: differences between a scarred and an unscarred uterus. Am J Obstet Gynecol. 2004; 19(1):425-9.

24. Amanael Gessesew MMM. Ruptured uterus-eight year retrospective analysis of the cause and management outcomes in Adigrat hospital Tigray region, Ethiopia. Ethiop J Health. 2002;16(3):241-5.

25. Noah Elias SA, Admasu K. Quarterly health bulletin policy and practice information for action. In: FDRoEMo, editor. Health. Addis Ababa; 2014

26. Sinha M, Gupta R, Gupta P, Rani R, Kaur R, Singh R. Uterine rupture: a seven year review at a tertiary care hospital in New Delhi, India. Indian J Community Med. 2016;41(1):45-9.

27. Al-Jufairi ZA, Sandhu AK, Al-Durazi KA. Risk factors of uterine rupture. Saudi Med J. 2001;22(8):702-4 PubMed PMID: 11573117.

28. Igwegbe AO, Eleje GU, Udegbunam Ol. Risk factors and perinatal outcome of uterine rupture in a low-resource setting. Niger Med J. 2013;54(6):415-9 PubMed PMID: 24665158. Pubmed Central PMCID: 3948966

29. Nahum GG. Uterine rupture in pregnancy. Medscape. 2016.

30. Latika S. A 10 year analysis of uterine rupture at a teaching institution. Obstet Gynecol India. 2006;56(6):502-6.

31. Guyot A, Carbonnel M, Frey C, Pharisien I, Uzan M, Carbillon L. [Uterine rupture: risk factors, maternal and perinatal complications]. J Gynecol Obstet 
Biol Reprod 2010;39(3):238-245. PubMed PMID: 20392573. Rupture uterine : facteurs de risque, complications maternelles et foetales.

32. Mbamara SU, Obiechina N, Eleje GU. An analysis of uterine rupture at the Nnamdi Azikiwe University teaching hospital Nnewi, Southeast Nigeria. Niger J Clin Pract. 2012;15(4):448-52.

33. Kaczmarczyk M, Sparen $P$, Terry $P$, Cnattingius $S$. Risk factors for uterine rupture and neonatal consequences of uterine rupture: a population-based study of successive pregnancies in Sweden. BJOG. 2007;114(10):1208-14 PubMed PMID: 17877673.

34. Turgut A, Ozler A, Siddik Evsen M, Ender Soydinc H, Yaman Goruk N, Karacor $\mathrm{T}$, et al. Uterine rupture revisited: predisposing factors, clinical features, management and outcomes from a tertiary care center in Turkey. Pak J Med Sci. 2013;29(3):753-7 PubMed PMID: 24353622. Pubmed Central PMCID: 3809304.

35. Sturzenegger K, Schaffer L, Zimmermann R, Haslinger C. Risk factors of uterine rupture with a special interest to uterine fundal pressure. J Perinat Med. 2016; PubMed PMID: 27235667.

36. Spencer C, Robarts P. Risk factors for uterine rupture and neonatal consequences of uterine rupture: a population-based study of successive pregnancies in Sweden. BJOG. 2008;115(3):415 author reply -6. PubMed PMID: 18190390.

37. Ronel D, Wiznitzer A, Sergienko R, Zlotnik A, Sheiner E. Trends, risk factors and pregnancy outcome in women with uterine rupture. Arch Gynecol Obstet. 2012;285(2):317-21 PubMed PMID: 21735183.

38. Egbe TO, Halle-Ekane GE, Tchente CN, Nyemb JE, Belley-Priso E. Management of uterine rupture: a case report and review of the literature. BMC Res Notes. 2016;9(492):2295-9.

39. Darlow K, Wolf H, Lawley R. Ruptured Uterus in Ethiopia: A series of 67 cases; GLOW book of abstracts liverpool. p. 29.

40. Aggrawal P, Terhase N. Unscarred uterine rupture: a retrospective study. Int J Reprod Contracept Obstet Gynecol. 2015;4(6):1997-9.

Ready to submit your research? Choose BMC and benefit from:

- fast, convenient online submission

- thorough peer review by experienced researchers in your field

- rapid publication on acceptance

- support for research data, including large and complex data types

- gold Open Access which fosters wider collaboration and increased citations

- maximum visibility for your research: over $100 \mathrm{M}$ website views per year

At $\mathrm{BMC}$, research is always in progress.

Learn more biomedcentral.com/submissions 